\title{
Gender differences in suicidal behavior in adolescents and young adults: systematic review and meta-analysis of longitudinal studies
}

\author{
Andrea Miranda-Mendizabal ${ }^{1,2} \cdot$ Pere Castellví $^{1,3} \cdot$ Oleguer Parés-Badell $^{1} \cdot$ Itxaso Alayo $^{1,4} \cdot$ \\ José Almenara ${ }^{5}$. Iciar Alonso ${ }^{6}$ - Maria Jesús Blasco ${ }^{1,2,4}$ - Annabel Cebrià ${ }^{7}$ - Andrea Gabilondo ${ }^{8,9}$. \\ Margalida Gili ${ }^{10,11} \cdot$ Carolina Lagares $^{12} \cdot$ José Antonio Piqueras ${ }^{13} \cdot$ Tiscar Rodríguez-Jiménez $^{13}$. \\ Jesús Rodríguez-Marín ${ }^{13} \cdot$ Miquel Roca $^{10,11} \cdot$ Victoria Soto-Sanz $^{13} \cdot$ Gemma Vilagut $^{1,4} \cdot$ Jordi Alonso $^{1,2,4}$
}

Received: 16 April 2018/Revised: 12 December 2018/Accepted: 19 December 2018/Published online: 12 January 2019

(C) The Author(s) 2019

\begin{abstract}
Objectives To assess the association between gender and suicide attempt/death and identify gender-specific risk/protective factors in adolescents/young adults.

Methods Systematic review (5 databases until January 2017). Population-based longitudinal studies considering nonclinical populations, aged 12-26 years, assessing associations between gender and suicide attempts/death, or evaluating their gender risk/protective factors, were included. Random effect meta-analyses were performed.

Results Sixty-seven studies were included. Females presented higher risk of suicide attempt (OR 1.96, 95\% CI 1.54-2.50), and males for suicide death (HR 2.50, 95\% CI 1.8-3.6). Common risk factors of suicidal behaviors for both genders are previous mental or substance abuse disorder and exposure to interpersonal violence. Female-specific risk factors for suicide attempts are eating disorder, posttraumatic stress disorder, bipolar disorder, being victim of dating violence, depressive symptoms, interpersonal problems and previous abortion. Male-specific risk factors for suicide attempt are disruptive behavior/conduct problems, hopelessness, parental separation/divorce, friend's suicidal behavior, and access to means. Male-specific risk factors for suicide death are drug abuse, externalizing disorders, and access to means. For females, no risk factors for suicide death were studied.

Conclusions More evidence about female-specific risk/protective factors of suicide death, for adolescent/young adults, is needed.
\end{abstract}

Keywords Gender · Suicide $\cdot$ Suicide attempt $\cdot$ Adolescents · Young adults · Risk factors

Electronic supplementary material The online version of this article (https://doi.org/10.1007/s00038-018-1196-1) contains supplementary material, which is available to authorized users.

Andrea Miranda-Mendizabal and Pere Castellvi contributed equally.

This article is part of the special issue "Adolescent transitions".

Jordi Alonso

jalonso@imim.es

Extended author information available on the last page of the article

\section{Introduction}

Suicide is a very serious public health concern. In 2016, there were an estimated 793,000 suicide deaths worldwide, representing an annual global age-standardized suicide rate of 10.5 per 100,000 population. Globally, it is the second leading cause of death among persons aged 15-29 years (World Health Organization 2016). In adolescents and young adults, suicide rates are 2-4 times higher in males than in females, while suicide attempts are 3-9 times more common in females (Wunderlich et al. 2001; Eaton et al. 2012). In developed countries, suicide mortality has been estimated to be 2-3 times higher in young males than females (Wasserman et al. 2005).

Within the context of suicide research, gender differences in suicidal behavior rates are known as the "Gender 
Paradox" (Canetto and Sakinofsky 1998). In adolescents and young adults, this paradox changes according to age (Canetto 2008; Rhodes et al. 2014a). Female suicide attempt rates increase with age, peaking in mid-adolescence (Lewinsohn et al. 2001; Boeninger et al. 2010; Thompson and Light 2011), whereas male suicide rates increase until early adulthood (World Health Organization 2014). Previous suicide attempts are one of the strongest predictors of suicide death (Kokkevi et al. 2012), especially among females. Gender differences in suicidal behavior may be explained by differences in emotional and behavioral problems (Kaess et al. 2011). The higher rates of suicide deaths among male youths may be associated with a higher prevalence of externalizing disorders (e.g., conduct disorder, substance abuse disorder, deviant behavior) (Mergl et al. 2015) and a preference for highly lethal methods (Värnik et al. 2008). In contrast, females are more prone to show internalizing disorders (e.g., anxiety, mood disorders) (Fergusson et al. 1993). These disorders may mediate the association with suicidal thoughts and behaviors (Peter and Roberts 2010; Mars et al. 2014).

To the best of our knowledge, no previous meta-analysis has assessed the association between gender and suicidal behaviors, or gender-specific determinants, in adolescents and young adults. Accurately identifying gender-specific risk and protective factors for suicidal behaviors is important to improve knowledge and to develop more effective suicide prevention programs. Therefore, we undertook a systematic review of the literature aiming to: (1) assess the magnitude of association between gender and suicide attempts and death; and (2) to identify genderspecific risk and protective factors of suicide attempts and death in adolescents and young adults.

\section{Methods}

This article is based on a broad, comprehensive systematic review of the risk and protective factors of suicidal behaviors in adolescents and young adults aged 12-26 years. The recommendations of the MOOSE guidelines for systematic reviews were followed (Table S1) (Stroup et al. 2000). The original search protocol was registered at PROSPERO. More information about the search strategy and selection criteria is provided in Text S1 (available online).

For this article, specific selection criteria were applied, including: (1) cohort studies assessing the association between gender and suicide attempts or death; and (2) cohort or case-control studies evaluating risk or protective factors for suicide attempts or death stratified by sex. For the assessment of gender with suicidal behaviors, casecontrol studies were excluded because the subjects were matched by sex, which may lead to underestimation of risk.
To assess suicide attempts, we considered females as the subpopulation at risk, with males as the comparison group; for suicide death, males were the subpopulation at risk (World Health Organization 2014). An exhaustive peer review process was used to classify risk and protective factors according to their definition in the primary studies, a previous exhaustive review of the literature (Evans et al. 2004) and the World Health Organization's socio-ecological model (World Health Organization 2014). The principal categories were as follows: sociodemographic and educational, individual negative life events and family adversity, psychiatric/psychological factors, personal factors and community factors.

A Cochrane Collaboration data collection form was adapted for data extraction (Higgins and Green 2008). Data were extracted by two reviewers, and a third assessed whether the information was entered properly and attempted to complete any missing data. If there were discrepancies, consensus was established among reviewers. The following data were extracted from each article: (1) sample size, (2) prevalence of females and males, (3) age range, (4) mean age, (5) country of recruitment, (6) study design, (7) suicide outcome, (8) type of sample recruited, (9) adjustment variables, and (10) ethics committee approval. For cohort studies, additional data extraction included: (1) weeks of follow-up, (2) number of suicide attempts or suicide deaths during follow-up, and (3) attrition rates. Information about sex-stratified risk and protective factors was obtained as follows: odds ratio (OR) and 95\% confidence intervals $(95 \% \mathrm{CI})$ or beta coefficients and standard errors (SE). Multivariate analyses were selected over bivariate analyses. If there were multiple publications on the same sample and factors, the results of the largest sample and longest follow-up were selected for the analyses.

\section{Quality assessment}

The Newcastle-Ottawa scale (NOS) was used to assess the quality of non-randomized studies (Wells et al. 2013), including: (1) selection of study groups, (2) comparability between groups, and (3) exposure in case-control studies or outcome in cohort studies. The NOS includes eight questions (four in selection, one in comparability, and three in exposure or outcome) with various response options; the response indicating the highest quality is assigned 1 point. One point can be granted for each question within the selection and exposure or outcome categories. For comparability, a maximum of 2 points can be given. The highest quality studies may receive a maximum of 9 points.

\section{Data synthesis}

Meta-analyses were performed when there were a minimum of two studies with usable data; random effect 
methods were used. Heterogeneity was assessed by visual inspection of forest plots, Galbraith plots, a Chi-square test to calculate $p$ value, and the Higgins test $\left(I^{2}\right)$, which describes the percentage of observed heterogeneity that would not be expected by chance. Heterogeneity was considered to be significant when $p$ was $<0.10$, and was classified as low $(<30 \%)$, moderate $(30 \%-50 \%)$, and severe $(>50 \%)$ (Higgins and Thompson 2002). Small study effects (including publication bias) were assessed through visual inspection of funnel plots and the Egger test.
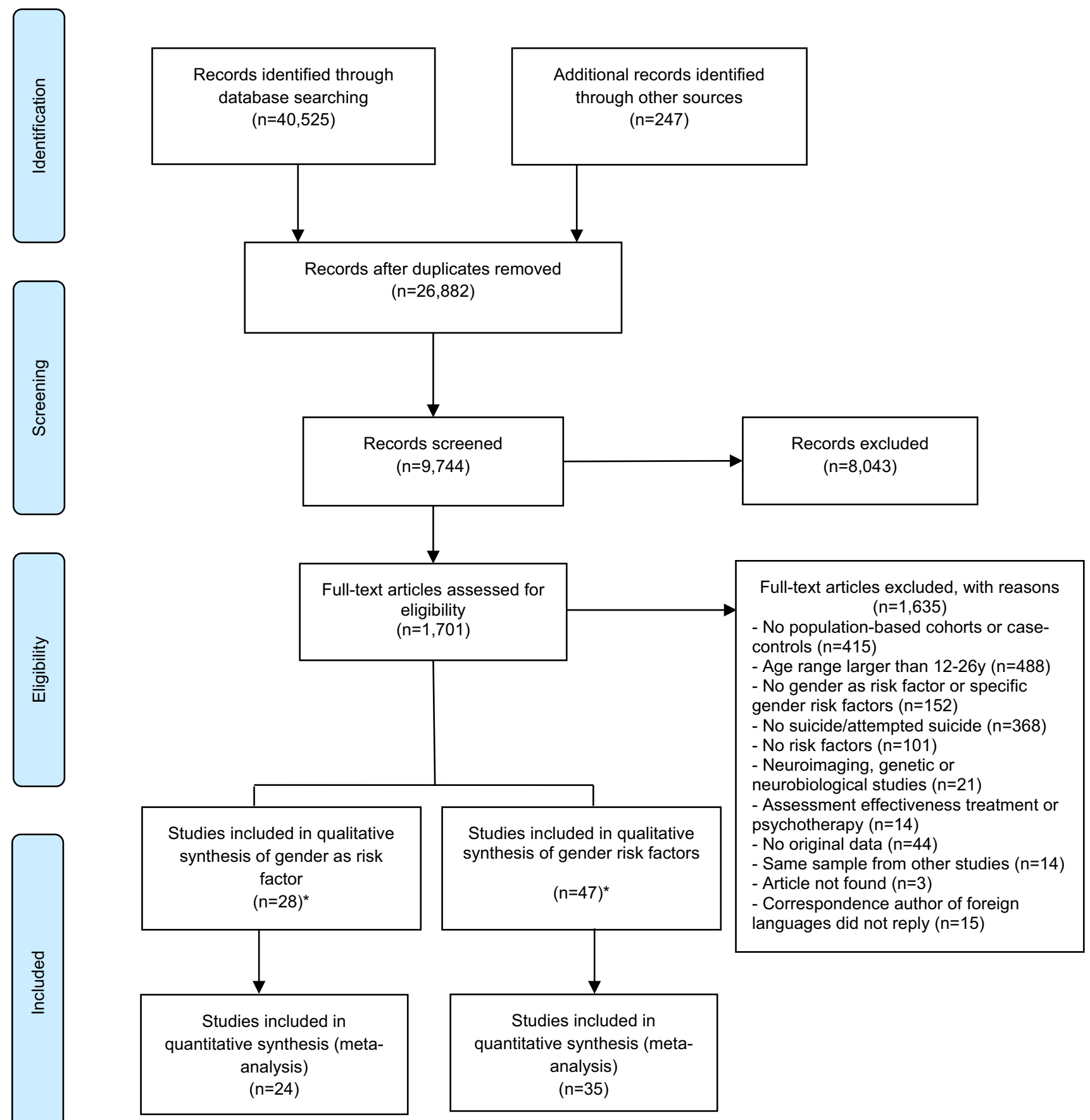

*Including 8 studies which assess gender as risk factor and specific gender risk factors.

Fig. 1 Modified version of PRISMA diagram of the included studies in the systematic review of gender differences in suicidal behavior in adolescents and young adults (covered up until January 2017) 


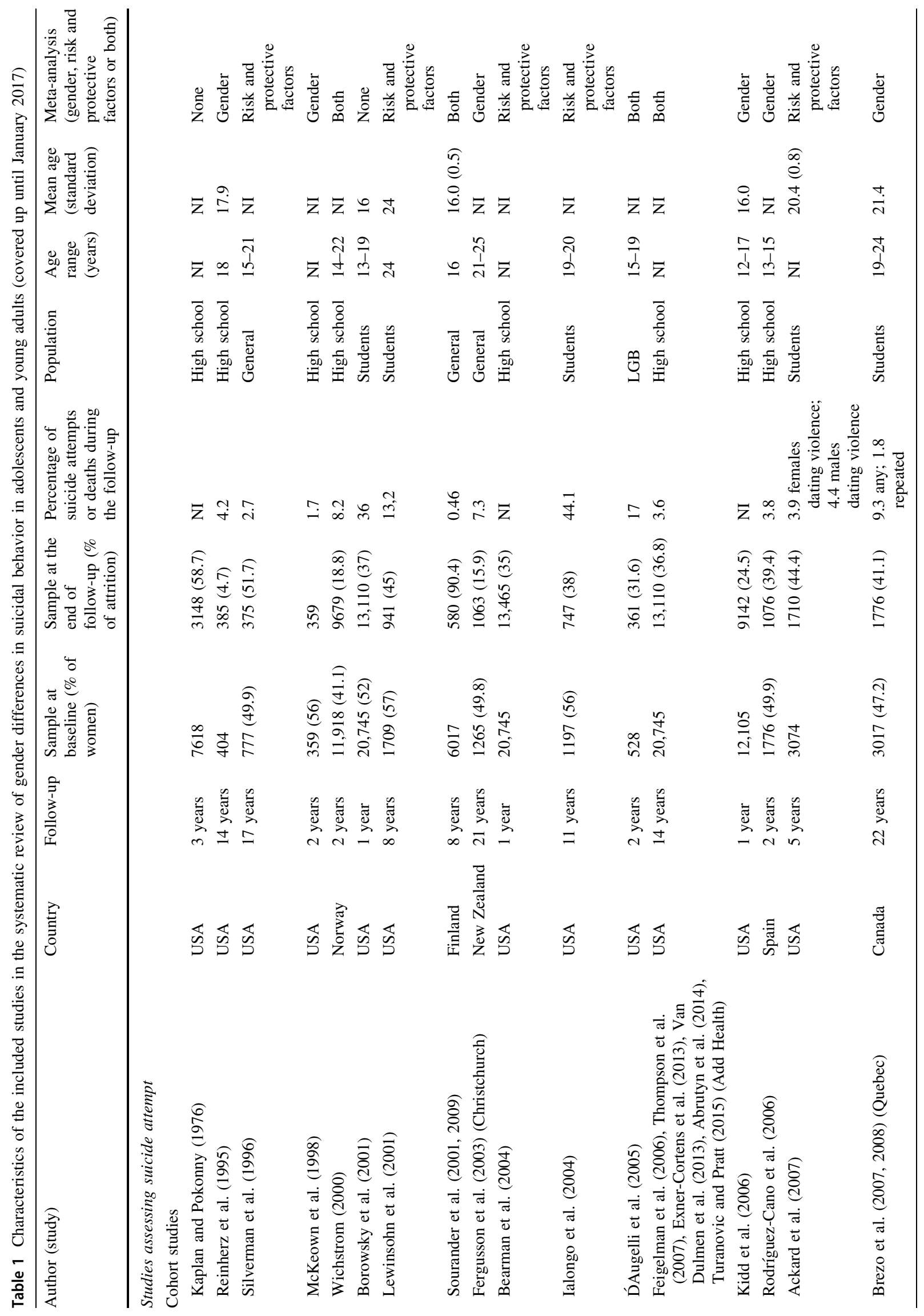




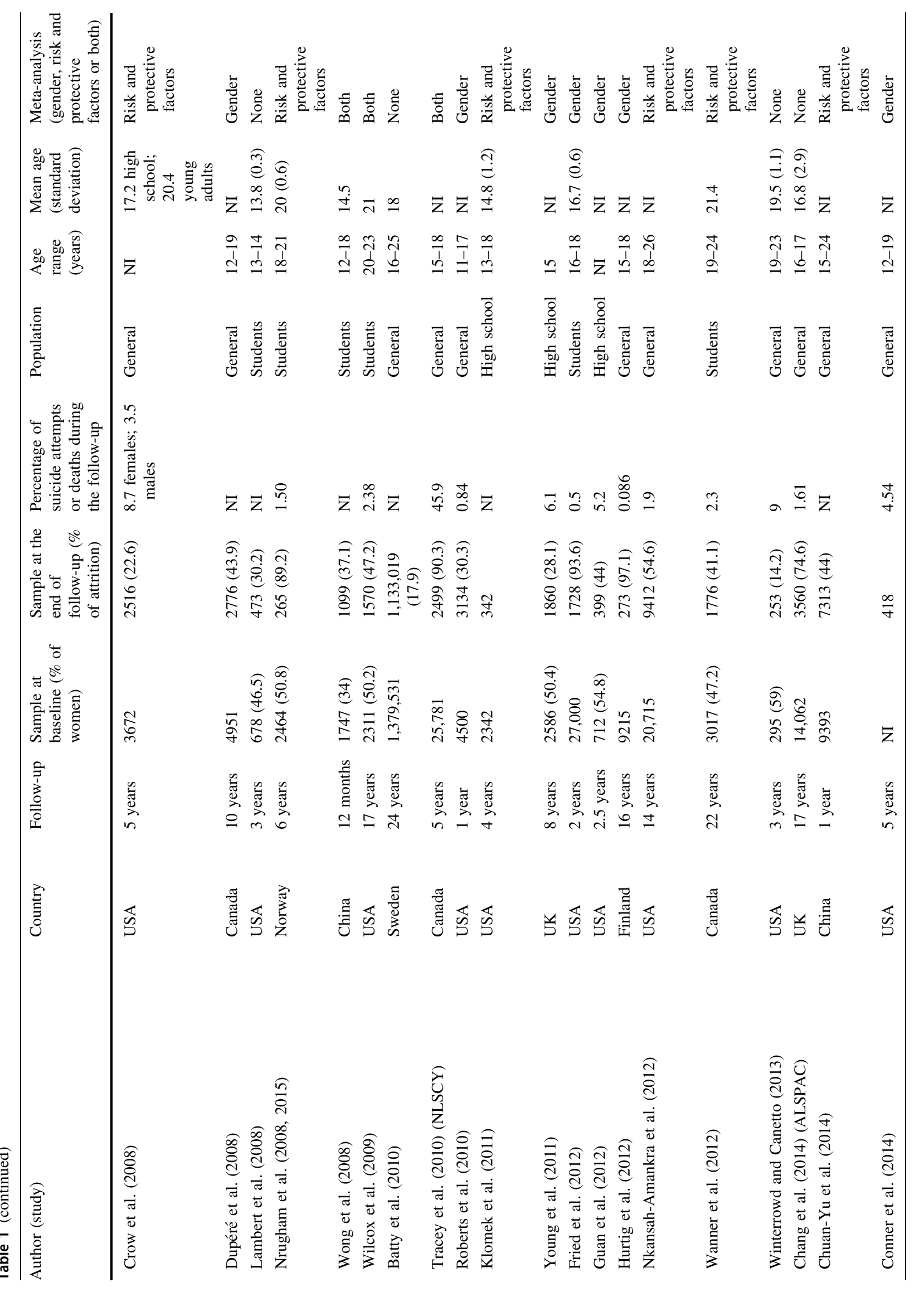


270

A. Miranda-Mendizabal et al.

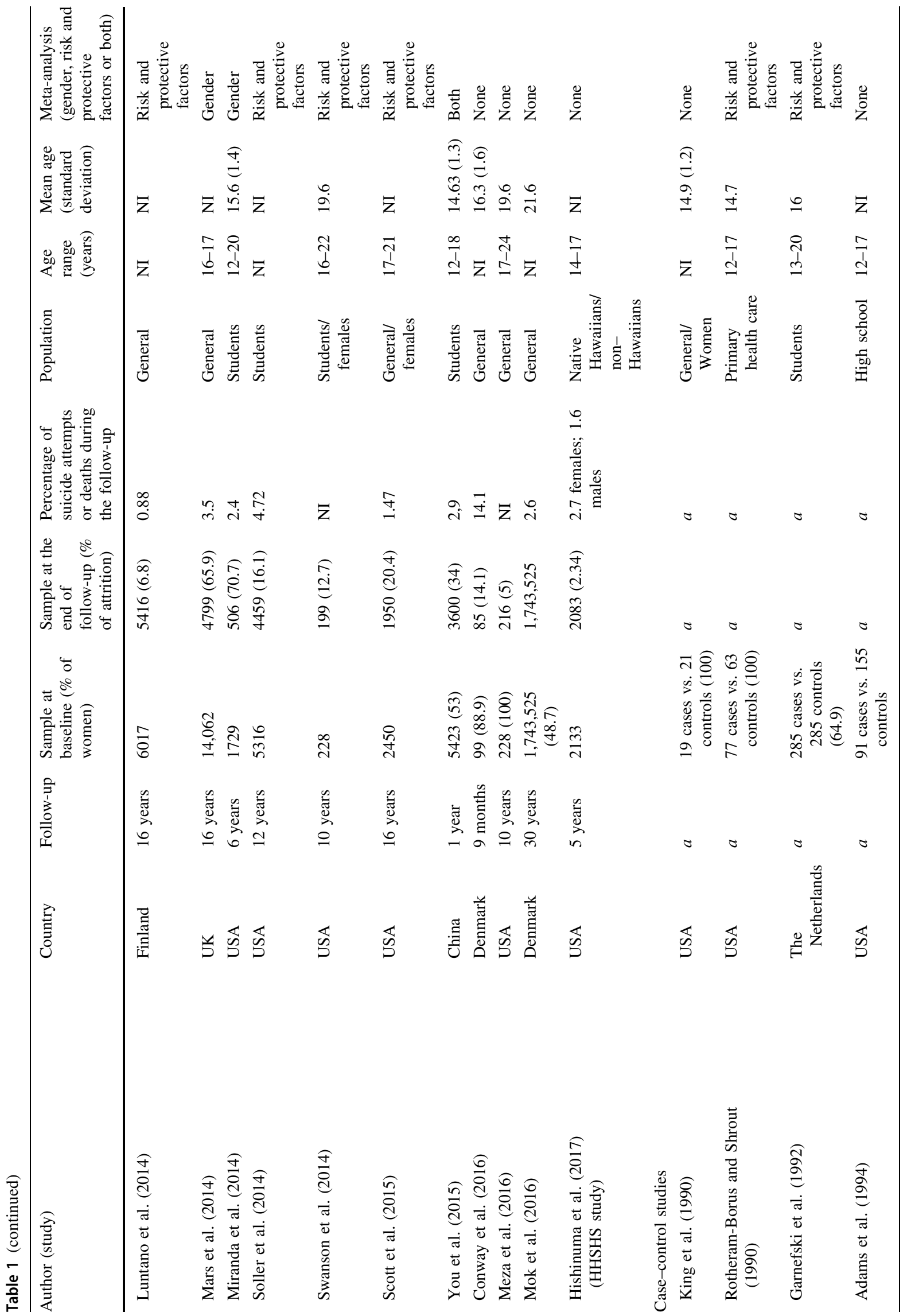

De Springer 


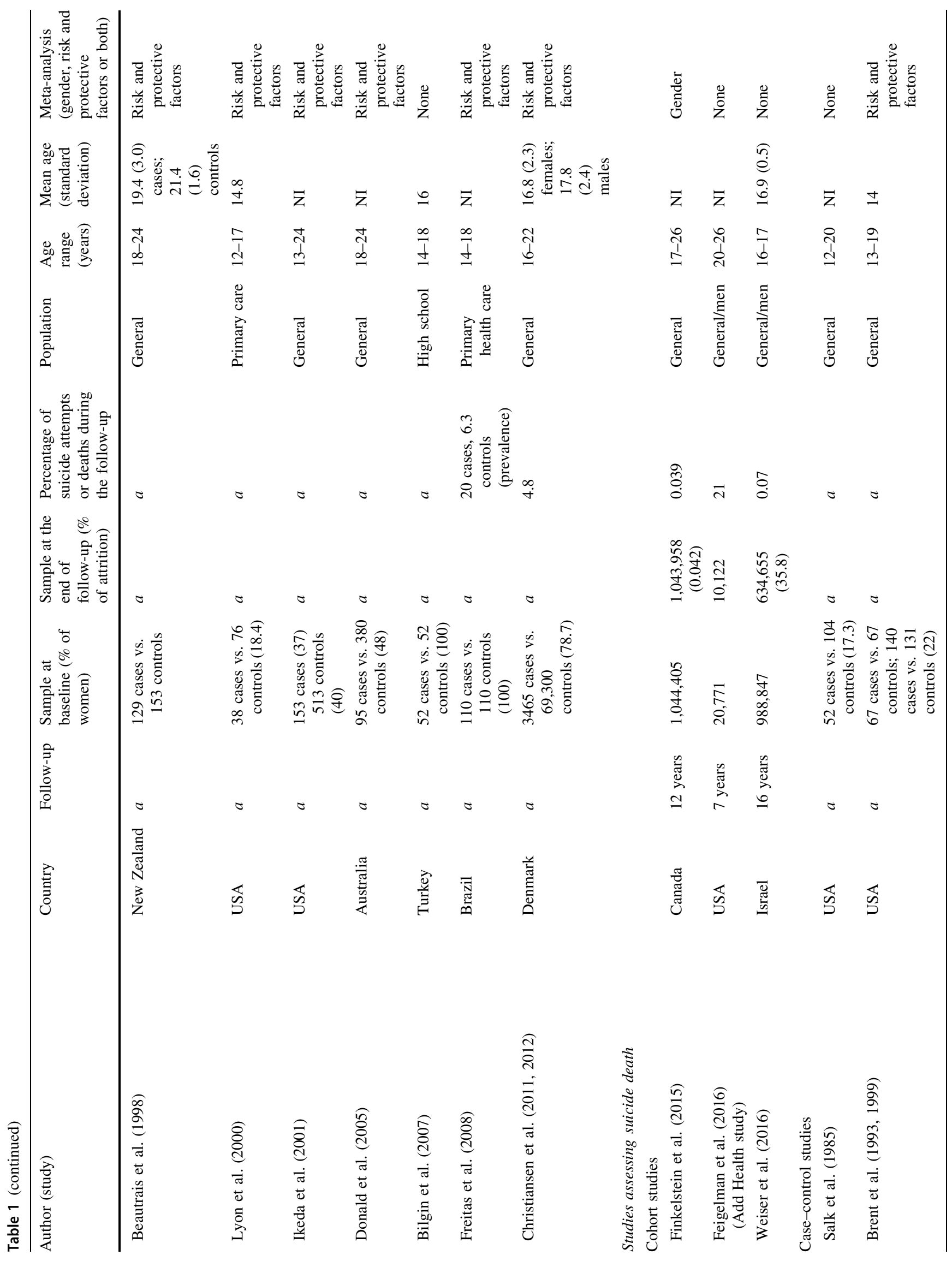




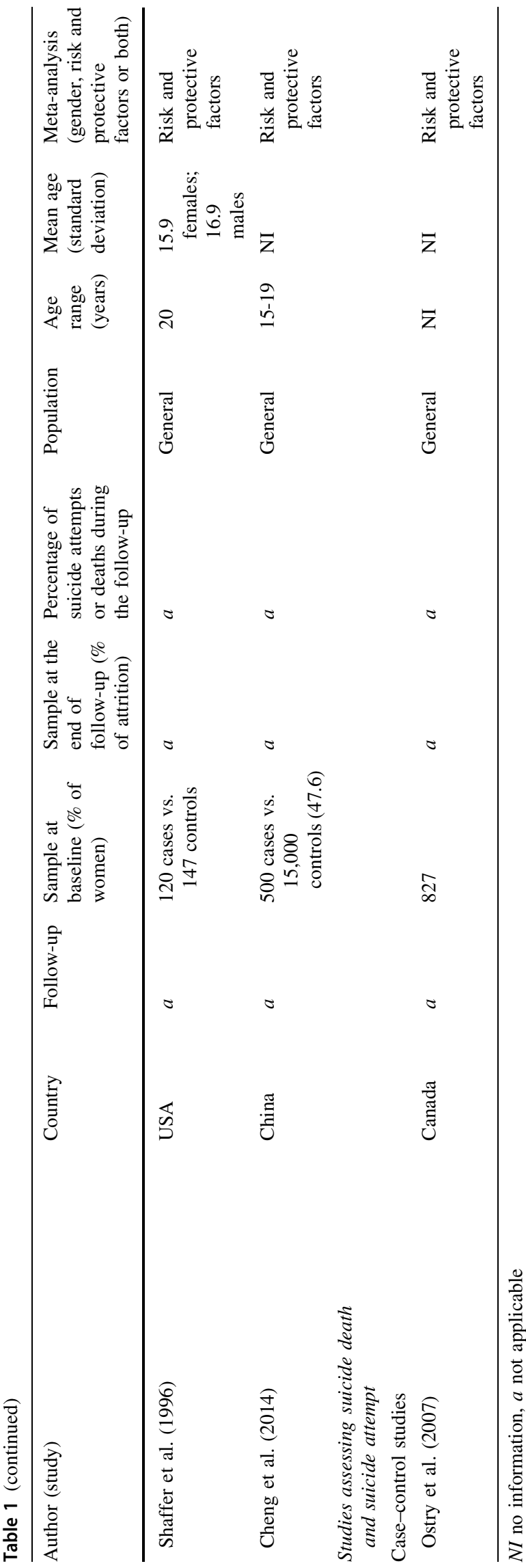

Sensitivity analyses were only conducted for the analysis of gender as a risk factor, according to two criteria: (1) publication year (studies published before the year 2000) and (2) NOS scale $<6$ points. Meta-analyses assessing the effects of risk and protective factors on suicide attempts and death were carried out. Due to the large number of figures, those not presented in this article are available upon request. STATA software version 13 was used.

\section{Results}

Of 26,882 potentially suitable articles, we identified 1701 full-text articles for eligibility. Of these, 1635 were excluded. Reasons for exclusion are detailed in Fig. 1. A total of 77 articles or publications were included, representing 67 distinct studies. Ten articles were excluded from the analyses as they reported results from the same samples but with shorter follow-up periods and without providing any additional information. The references of all included articles are provided in supplementary Text S2. Nineteen studies assessed the association between gender and suicide attempts; one assessed the association between gender and suicide death; 39 assessed sex-specific risk and/or protective factors for the outcomes; and eight assessed both gender and sex-specific risk and/or protective factors. Results are presented separately for suicide attempts and suicide death.

\section{Quality of reviewed studies}

No relevant differences between the included studies were observed in the selection domain. For comparability, 39 studies achieved two points. The lowest scores were found in exposure or outcome domains: Only 15 studies achieved 1 point in the question about the ascertainment of the outcome or exposure, because most studies included selfreported data without confirmatory records; 34 studies received 1 point because the length of follow-up was $\geq 6$ years; and 25 studies received 0 points for adequacy of follow-up (attrition rates were $>25 \%$ ). More information is detailed in Table S2 (available online).

\section{Gender as a risk factor for suicidal behavior}

\section{Suicide attempts}

Articles were published between 1995 and 2017, including samples predominantly from the USA $(n=13)$ and Canada $(n=4)$. Participation rates ranged from $3 \%$ to almost $98 \%$. A summary of the most relevant characteristics of the included studies is presented in Table 1 . 


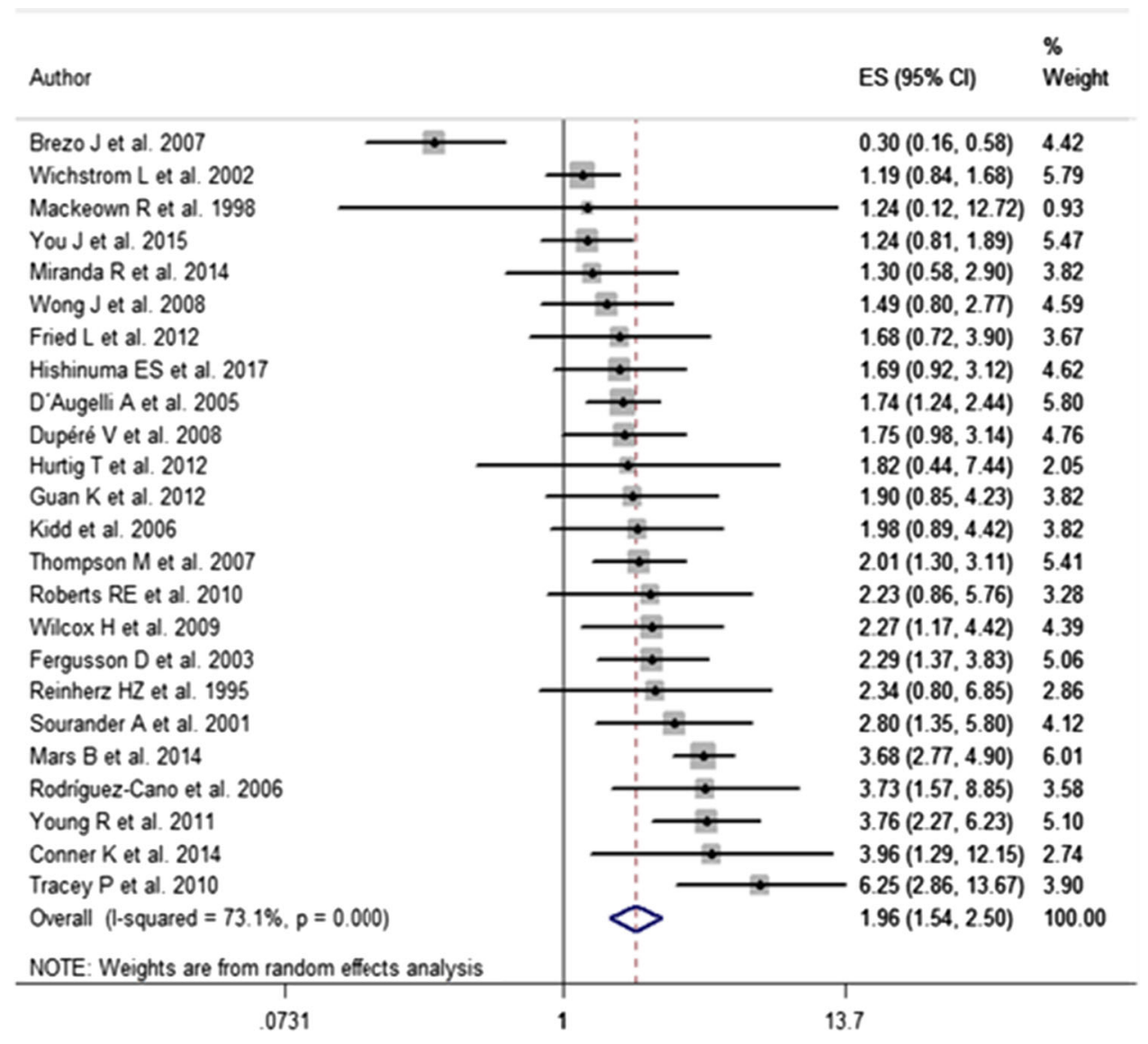

Fig. 2 Forest plot of being female as risk factor of suicide attempt—results of the systematic review of gender differences in suicidal behavior in adolescents and young adults (covered up until January 2017)

Of the 27 studies assessing the association between gender and suicide attempts, 24 were included in the metaanalysis. Three studies were excluded because the data were either non-extractable or did not allow comparisons. Compared with males, females showed a significantly higher pooled risk of suicide attempts (OR 1.96, 95\% CI 1.54-2.50), although high heterogeneity was observed $\left(I^{2}=73.1 \% ; p<0.001\right)$ (Fig. 2). The funnel plot appeared asymmetric, but the Egger test did not suggest the existence of any publication bias $(p=0.847)$. After sensitivity analyses, according to publication year and quality score, no significant changes were seen.

\section{Suicide death}

One cohort study explored the association between gender and suicide death, including a sample of $1,043,958$ subjects. A total of 20,471 surviving adolescents (median age 16 years; IQR 15-18), attended in the emergency department for a first self-poisoning episode, were followed from the date of discharge until death or the end of the study, whichever occurred first. Fifty matched population-based reference individuals were selected for each surviving adolescent $(n=1,023,487)$. After a median follow-up time of 7.2 years (IQR 4.2-9.7), the results showed that 126 individuals $(0.6 \%)$ in the self-poisoning group and 286 $(0.03 \%)$ in the reference group died by suicide. After a selfpoisoning episode, death from suicide was more than twice as likely among males compared with females (HR 2.5, 95\% CI 1.8-3.6) (Finkelstein et al. 2015).

\section{Specific risk factors for suicidal behavior stratified by gender}

A full summary of results for all risk and protective factors assessed is detailed in Table 2 .

\section{Suicide attempts}

Individual negative life events and family adversity Risk factors for suicide attempts common to both genders included bullying (females: OR 6.30, 95\% CI 1.53-25.90; males: OR 3.8, 95\% CI 1.01-14.30), childhood maltreatment (females: OR 3.77, 95\% CI 2.13-6.68; males: OR $2.76,95 \%$ CI 1.20-6.36), community violence (females: OR 1.68, 95\% CI 1.42-1.99; males: OR 1.83, 95\% CI 
Table 2 Meta-analysis results of gender risk and protective factors of suicidal behavior among adolescents and young adults-results of the systematic review of gender differences in suicidal behavior in adolescents and young adults (covered up until January 2017)

\begin{tabular}{|c|c|c|c|c|c|c|c|c|c|c|}
\hline \multirow[t]{2}{*}{ Factor(s) } & \multicolumn{5}{|l|}{ Female } & \multicolumn{5}{|l|}{ Male } \\
\hline & $\begin{array}{l}\text { Studies } \\
(n)\end{array}$ & $\begin{array}{l}\text { Samples } \\
(n)\end{array}$ & OR & $95 \% \mathrm{CI}$ & $I^{2}$ & $\begin{array}{l}\text { Studies } \\
(n)\end{array}$ & $\begin{array}{l}\text { Samples } \\
(n)\end{array}$ & OR & $95 \% \mathrm{CI}$ & $I^{2}$ \\
\hline
\end{tabular}

Suicide attempt

Sociodemographic and educational

$\begin{array}{ll}\text { Academic factors } & 3 \\ \text { Low socioeconomic status } & 2 \\ \text { Parental education } & 2 \\ \text { Race/ethnicity } & 3\end{array}$

Individual negative life events and family adversity

\begin{tabular}{|c|c|c|c|c|c|c|c|c|c|c|}
\hline \\
\hline Any negative life event ${ }^{a}$ & 6 & 6 & 1.31 & $0.93-1.86$ & 94.7 & 6 & 6 & 1.22 & $0.98-1.51$ & 75.8 \\
\hline Bullying & 1 & 1 & 6.30 & $1.53-25.90$ & NA & 1 & 1 & 3.8 & 1.01-14.30 & NA \\
\hline Childhood maltreatment & 3 & 5 & 3.77 & $2.13-6.68$ & 69.6 & 3 & 4 & 2.76 & $1.20-6.36$ & 72.8 \\
\hline Community violence & 3 & 3 & 1.68 & $1.42-1.99$ & $\mathbf{0}$ & 2 & 2 & 1.83 & $1.48-2.26$ & $\mathbf{0}$ \\
\hline Conflicts with partner & 2 & 2 & 1.2 & $0.87-1.65$ & 67.6 & 1 & 1 & 1.05 & $0.52-2.13$ & NA \\
\hline Dating violence & 2 & 3 & 2.19 & $1.29-3.71$ & $\mathbf{0}$ & 3 & 3 & 1.45 & $0.54-3.86$ & 32.3 \\
\hline $\begin{array}{l}\text { Parental separation or } \\
\text { divorce }\end{array}$ & 7 & 8 & 1.07 & $0.88-1.29$ & 27.2 & 7 & 8 & 1.56 & $1.01-2.41$ & 73.4 \\
\hline $\begin{array}{l}\text { Family history of mental } \\
\text { disorders and abuse }\end{array}$ & 2 & 3 & 2.27 & $1.78-2.89$ & 18.8 & 3 & 6 & 2.63 & $1.99-3.47$ & 98.6 \\
\hline $\begin{array}{l}\text { Family previous suicidal } \\
\text { behavior }\end{array}$ & 2 & 3 & 2.10 & $0.97-4.58$ & 93.2 & 3 & 4 & 2.84 & $1.87-4.33$ & 42.4 \\
\hline Interpersonal difficulties & 2 & 3 & 1.13 & $1.03-1.24$ & $\mathbf{0}$ & 1 & 2 & 1.04 & $0.90-1.21$ & 0 \\
\hline \multicolumn{11}{|l|}{ Psychiatric and psychological } \\
\hline \multicolumn{11}{|l|}{ Psychiatric } \\
\hline ADHD & 3 & 4 & 0.79 & $0.19-3.21$ & 78.8 & 1 & 1 & 4.50 & $0.96-21.20$ & NA \\
\hline Alcohol abuse disorder & 2 & 2 & 2.69 & $1.32-5.50$ & $\mathbf{0}$ & 2 & 2 & 2.14 & $1.09-4.20$ & $\mathbf{0}$ \\
\hline Alcohol use & 3 & 3 & 1.16 & $0.83-1.62$ & 78.0 & 3 & 3 & 1.10 & $0.94-1.27$ & 6.3 \\
\hline Anxiety disorder & 3 & 4 & 2.03 & $1.77-2.33$ & $\mathbf{0}$ & 3 & 5 & 3.79 & $2.05-7.01$ & 91.8 \\
\hline $\begin{array}{l}\text { Any mental disorder or } \\
\text { abuse }\end{array}$ & 10 & 36 & 3.37 & $2.52-4.51$ & 88.4 & 6 & 27 & 4.23 & $3.28-5.47$ & 0.8 \\
\hline Bipolar disorder & 2 & 2 & 1.43 & $1.20-1.70$ & $\mathbf{0}$ & No data & & & & \\
\hline Conduct disorder & 1 & 1 & 2.31 & $0.50-10.65$ & NA & 1 & 1 & 0.80 & $0.10-6.53$ & NA \\
\hline Drug abuse disorder & 3 & 6 & 4.44 & $2.51-7.83$ & 72.2 & 2 & 5 & 3.11 & 2.01-4.84 & $\mathbf{0}$ \\
\hline Drugs use & 3 & 3 & 3.2 & $0.68-14.95$ & 78.9 & 3 & 3 & 3.03 & $0.64-14.32$ & 87.7 \\
\hline Eating disorder & 1 & 2 & 5.27 & $2.04-13.60$ & $\mathbf{0}$ & No data & & & & \\
\hline Gambling disorder & 1 & 1 & 4.13 & $0.54-31.85$ & NA & 1 & 1 & 1.01 & $0.14-7.35$ & NA \\
\hline Major depressive disorder & 4 & 5 & 4.49 & $2.18-9.23$ & 78.4 & 3 & 4 & 6.07 & $1.74-21.20$ & 83.6 \\
\hline NSSI & 2 & 2 & 2.03 & $0.52-7.89$ & 88.2 & 1 & 1 & 1.00 & $0.92-1.09$ & NA \\
\hline Personality disorder & 1 & 2 & 7.89 & $3.81-16.35$ & $\mathbf{0}$ & 2 & 2 & 5.13 & $2.63-10.01$ & $\mathbf{0}$ \\
\hline PTSD & 2 & 2 & 2.96 & $1.32-6.62$ & 38.6 & 1 & 1 & 3.57 & $0.58-22.16$ & NA \\
\hline Previous suicidal ideation & 4 & 4 & 4.39 & 2.31-8.34 & 77.5 & 4 & 4 & 3.97 & $1.40-11.24$ & 84.5 \\
\hline Previous suicide attempts & 5 & 7 & 6.96 & $3.75-12.91$ & 58.2 & 1 & 2 & 31.33 & 9.36-104.88 & $\mathbf{0}$ \\
\hline \multicolumn{11}{|l|}{ Psychological } \\
\hline Aggressiveness & No data & & & & & 1 & 1 & 1.15 & $0.67-1.98$ & NA \\
\hline Anxiety symptoms & No data & & & & & 1 & 1 & 0.64 & $0.40-1.03$ & NA \\
\hline Depressive symptoms & 10 & 10 & 1.15 & $1.04-1.28$ & 66.9 & 6 & 6 & 1.26 & $0.98-1.62$ & 61.5 \\
\hline Disruptiveness & 3 & 5 & 2.54 & $0.67-9.60$ & 80.7 & 2 & 3 & 8.78 & $2.77-27.84$ & 75.6 \\
\hline Hopelessness & 3 & 3 & 1.55 & $0.71-3.42$ & 69.4 & 3 & 3 & 1.74 & $1.04-2.94$ & $\mathbf{0}$ \\
\hline Low self-esteem & 4 & 4 & 1.46 & $0.78-2.74$ & 87.0 & 4 & 4 & 1.22 & $0.95-1.57$ & 0 \\
\hline
\end{tabular}


Table 2 (continued)

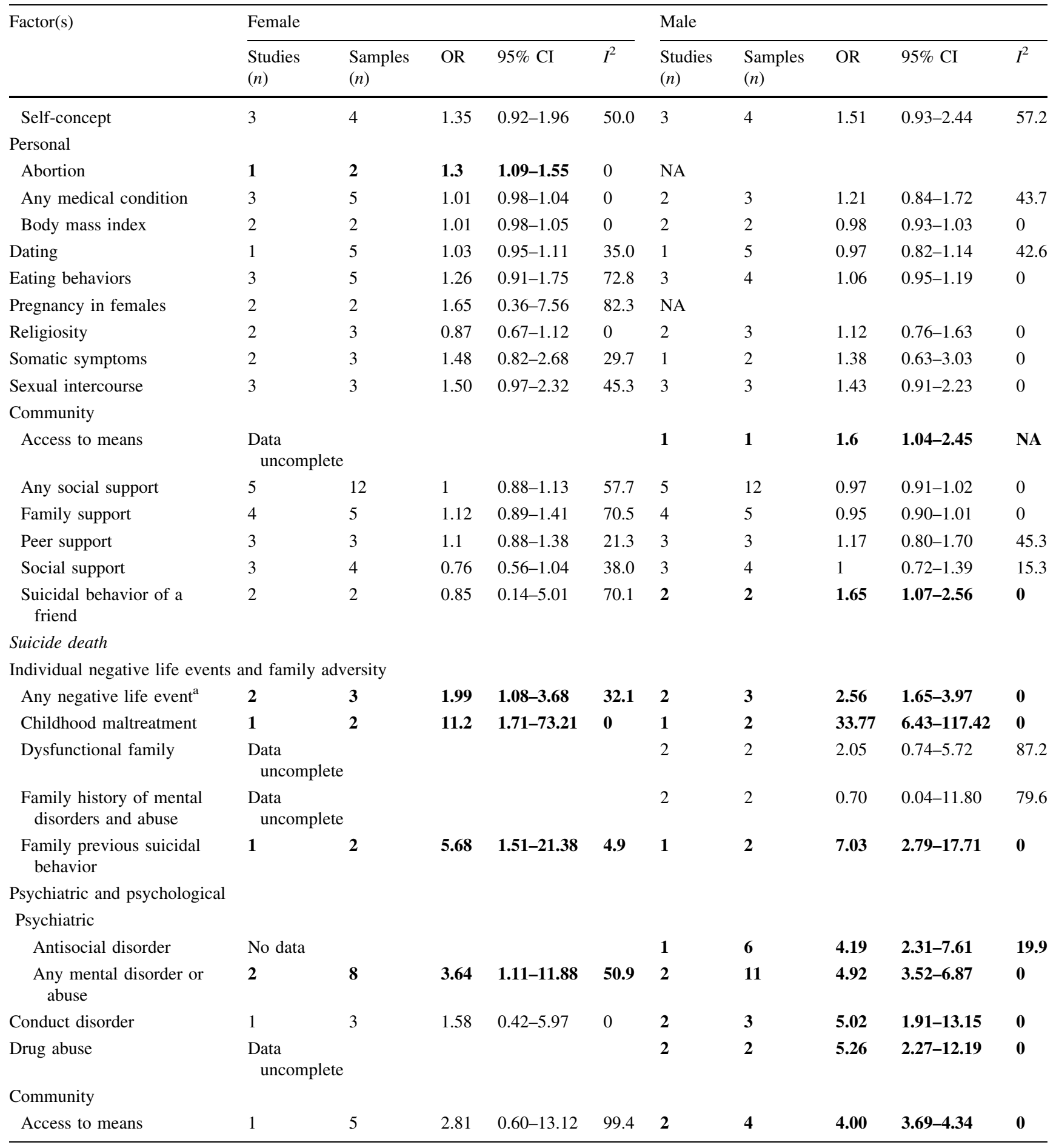

95\% CI 95\% confidence intervals, OR odds ratio, PTSD posttraumatic stress disorder, ADHD attention deficit hyperactivity disorder, NSSI nonsuicidal self-injuries, $N A$ not applicable

${ }^{a}$ Death of a parent, parental divorce, losing boy/girlfriend, trauma exposure, major events 
1.48-2.26), and a family history of mental disorders, alcohol or drug abuse (females: OR 2.27, 95\% CI 1.78-2.89; males: OR 2.63, 95\% CI 1.99-3.47). Dating violence (OR 2.19, 95\% CI 1.29-3.71) and having experienced interpersonal difficulties were associated with higher rates of suicide attempts in females (OR 1.13, 95\% CI 1.03-1.24). Parental separation or divorce (OR 1.56, 95\% CI 1.01-2.41) and previous suicidal behavior in the family (OR 2.84, 95\% CI 1.87-4.33) were associated with suicide attempts only among males.

Psychiatric and psychological The risk factors for suicide attempts, common to both genders, included previous suicidal ideation (females: OR 4.39, 95\% CI 2.31-8.34; males: OR 3.97, 95\% CI 1.40-11.24), previous suicide attempts (females: OR 6.96, 95\% CI 3.75-12.91; males: OR 31.33, 95\% CI 9.36-104.88), and a history of any mental disorder (females: OR 3.37, 95\% CI 2.52-4.51; males: OR 4.27, 95\% CI 3.28-5.47), specifically anxiety disorder (females: OR 2.03, 95\% CI 1.77-2.33; males: OR 3.79, 95\% CI 2.05-7.01), major depressive disorder (MDD) (females: OR 4.49, 95\% CI 2.18-9.23; males: OR 6.07, 95\% CI 1.74-21.20), and personality disorders (females: OR 7.89, 95\% CI 3.81-16.35; males: OR 5.13, 95\% CI 2.63-10.01). Other risk factors were alcohol abuse (females: OR 2.69, 95\% CI 1.32-5.50; males: OR 2.14, 95\% CI 1.09-4.20) and drug abuse (females: OR 4.44, 95\% CI 2.51-7.83; males: OR 3.11, 95\% CI 2.01-4.84).

Factors that increased the risk of suicide attempts only among females were bipolar disorder (OR 1.43, 95\% CI 1.20-1.70), eating disorders (OR 5.27, 95\% CI 2.04-13.60), posttraumatic stress disorder (PTSD) (OR 2.96, 95\% CI 1.32-6.62), and depressive symptoms (OR 1.15, 95\% CI 1.04-1.28). Factors significantly associated with suicide attempts among males were disruptiveness (OR 8.78, 95\% CI 2.77-27.84) and hopelessness (OR 1.74, 95\% CI 1.04-2.94).

Personal Among females, a previous abortion significantly increased the risk of suicide attempts (OR 1.3, 95\% CI 1.09-1.55).

Community Male adolescents and young adults with access to means (e.g., firearms, pesticides, toxic gas) had a significant OR for suicide attempts compared with those who did not (OR 1.6, 95\% CI 1.04-2.45). Exposure to the suicidal behavior of a friend (OR 1.65, 1.07-2.56) was significantly associated only in males.

\section{Suicide death}

Individual negative life events and family adversity For both genders, any negative life event (e.g., death of a parent, losing boy/girlfriend) was a common risk factor for suicide death (females: OR 1.99, 95\% CI 1.08-3.68; males: OR 2.56 , 95\% CI 1.65-3.97). Other factors were childhood maltreatment (females: OR 11.20, 95\% CI 1.71-73.21; males: OR 33.77, 95\% CI 6.43-177.22) and previous suicidal behavior in the family (females: OR 5.68, 95\% CI 1.51-21.38; males: OR 7.03, 95\% CI 2.79-17.71).

Psychiatric and psychological Among both genders, the risk of suicide death was increased by a history of any mental disorder or abuse (females: OR 3.64, 95\% CI 1.11-11.18; males: OR 4.92, 95\% CI 3.52-6.87). Among males, significant associations were found with conduct disorder (OR 5.02, 95\% CI 1.91-13.15), antisocial disorder (OR 4.19, 95\% CI 2.31-7.61), and drug abuse (OR 5.26, $95 \%$ CI $5.26 ; 2.27-12.19)$.

Community Among males, the risk of suicide was increased by access to means (OR 4.00, 95\% CI 3.69-4.34). Among females, the risk was also increased, but not significantly so.

For both genders, nonsignificant associations were observed between the following risk and protective factors for suicide attempts: any negative life event, conflicts with the partner, attention deficit hyperactivity disorder, alcohol and drug use, conduct disorder, gambling disorder, nonsuicidal self-injuries, low self-esteem, any kind of support, and all the personal factors assessed except abortion. For suicide death, nonsignificant associations were found with having a dysfunctional family and a family history of mental disorders.

\section{Discussion}

We estimated the pooled risk of suicidal behaviors among adolescents and young adults and found that females had an almost twofold higher risk of suicide attempts than males, while males had an almost threefold higher risk of dying by suicide than females. Our meta-analysis has identified risk factors for both suicide attempts and death, which are common to male and female adolescents and young adults: exposure to any form of interpersonal violence and a history of mental or substance abuse disorder. Risk factors for suicide attempts included a history of previous suicidal thoughts and behaviors and a family history of mental disorders and abuse. For suicide death, a common risk factor was a family history of suicidal behavior. We also identified risk factors for suicide attempts in adolescents and young adults that were more specific for females or males, and for suicide death, which were specific for males only (Table 3). Finally, no significant associations were found between the protective factors assessed and suicide attempts and death. 
Table 3 Significant meta-analyses results of gender risk factors of suicidal behavior among adolescents and young adults-results of the systematic review of gender differences in suicidal behavior in adolescents and young adults (covered up until January 2017)

\begin{tabular}{|c|c|c|c|c|}
\hline \multirow[t]{3}{*}{ Factor(s) } & \multicolumn{4}{|c|}{ Severity $^{\mathrm{a}}$} \\
\hline & \multicolumn{2}{|c|}{ Suicide death } & \multicolumn{2}{|c|}{ Suicide attempt } \\
\hline & Female & Male & Female & Male \\
\hline \multicolumn{5}{|l|}{ Individual negative life events and family adversity } \\
\hline Childhood maltreatment & +++ & +++ & ++ & ++ \\
\hline Family previous suicidal behavior & +++ & +++ & & ++ \\
\hline Any negative life event ${ }^{b}$ & + & ++ & & \\
\hline Bullying & & & +++ & ++ \\
\hline Family history of mental disorders and abuse & & & ++ & ++ \\
\hline Community violence & & & + & + \\
\hline Parental separation or divorce & & & & + \\
\hline \multicolumn{5}{|l|}{ Psychiatric and psychological } \\
\hline Any mental disorder or abuse & ++ & ++ & & \\
\hline Drug abuse & & +++ & & \\
\hline Conduct disorder & & ++ & & \\
\hline Antisocial disorder & & ++ & & \\
\hline Major depressive disorder & & & ++ & +++ \\
\hline Personality disorder & & & +++ & +++ \\
\hline Previous suicide attempts & & & +++ & +++ \\
\hline Anxiety disorder & & & ++ & ++ \\
\hline Alcohol abuse & & & ++ & ++ \\
\hline Drug abuse & & & ++ & ++ \\
\hline Previous suicidal ideation & & & ++ & ++ \\
\hline Eating disorder & & & +++ & \\
\hline PTSD & & & ++ & \\
\hline Dating violence & & & ++ & \\
\hline Bipolar disorder & & & + & \\
\hline Interpersonal difficulties & & & + & \\
\hline Depressive symptoms & & & + & \\
\hline Disruptiveness & & & & +++ \\
\hline Hopelessness & & & & + \\
\hline \multicolumn{5}{|l|}{ Personal } \\
\hline Abortion & & & + & \\
\hline \multicolumn{5}{|l|}{ Community } \\
\hline Suicidal behavior of a friend & & & & + \\
\hline Access to means & & ++ & & + \\
\hline
\end{tabular}

PTSD posttraumatic stress disorder

${ }^{\mathrm{a}}$ Severity according to odds ratio values $+>1$ to $<2,++\geq 2$ to $<5,+++\geq 5$. ${ }^{\mathrm{b}}$ Death of a parent, parental divorce, losing boy/girlfriend, trauma exposure, major events

\section{Gender as a risk factor for suicidal behaviors}

Girls aged between 12 and 24 years have a higher lifetime prevalence (Evans et al. 2005; Kokkevi et al. 2012; Nock et al. 2013) and 12-month incidence (Evans et al. 2005; Afifi et al. 2007) of suicide attempts. The incidence and lethality of suicide attempts might be reduced among female youths by identifying high risk cases. Young women may be more likely to engage in help-seeking behaviors, to have a general readiness to talk about emotional problems (Beautrais 2002) and to frequently identify friends and professionals as sources of help (Rickwood 
et al. 2005). Moreover, considering that there is a high prevalence of mental disorders among youth who die by suicide (Renaud et al. 2008), help-seeking behaviors and contact with the health care system may diminish the risk of suicide among girls (Rhodes 2013).

In line with previous studies (Canetto and Sakinofsky 1998; Beautrais 2002), our results show that male youths have a considerably higher risk than females of dying by suicide. Higher mortality among males might be explained by the use of more lethal means, such as firearms and hanging methods (Beautrais 2003; Rhodes et al. 2014b), while drug poisoning is more frequent in females (Beautrais 2003; Mergl et al. 2015). Young males may be less predisposed to help-seeking behaviors in an attempt to exhibit masculine behaviors (Rhodes et al. 2014a). This association may be moderated by intentionality, impulsiveness, and aggressiveness (Beautrais 2003). Furthermore, a male tendency to adopt avoidance strategies (Gould et al. 2004) might make it more difficult for them to cope with emotional and behavioral problems.

An additional explanation for gender differences in suicide deaths may be misclassification. Suicide deaths tend to be reported as accidental or underdetermined due to shame, stigma, or lack of evidence (Beautrais et al. 1996). However, in a Canadian study that reclassified accidental or underdetermined deaths and suspected suicides, the gender gap of suicide rates remained for youths aged 16-25 years (Gould et al. 2004).

\section{Common and gender-specific risk factors for suicidal behaviors}

\section{Common risk factors}

For suicide attempts, risk factors common to both genders include bullying, childhood maltreatment, community violence, previous suicidal thoughts and behaviors, any previous mental disorder or alcohol or drug abuse, and a family history of mental disorders and substance abuse. For suicide death, common risk factors include childhood maltreatment, any negative life events, and a family history of suicidal behavior.

Early exposure to traumatic life events, such as childhood maltreatment and bullying, implies complex processes that may increase vulnerability for suicidal behaviors, in both genders (Wilcox et al. 2009), including psychopathology (e.g., PTSD) (Wilcox et al. 2010) or maladaptive personality features (ÓBrien and Sher 2013). Specifically, exposure to any childhood physical and/or psychological abuse is associated with a lack of social support and risky health behaviors, which consequently are related to poorer mental health and well-being (Sheikh et al. 2016). However, it seems that childhood traumatic experiences favor the development of internalizing symptoms in adulthood due to dissatisfaction with social connections more than a real lack of external support (Sheikh 2018). Furthermore, our findings agree with the results of an extended study conducted in eight eastern European countries, showing that individuals with traumatic childhood experiences were at a significantly increased risk of health-harming behaviors including suicide attempts (Bellis et al. 2014). We found an association between PTSD and suicide attempts among females, and the single study with males showed a threefold risk, which was statistically nonsignificant, probably due to the scarcity of data. No data were found to estimate the association between PTSD and suicide death.

A history of previous suicidal thoughts and behaviors is one of the most frequent common risk factors for later suicide attempts (Borges et al. 2008; O'Connor et al. 2015) and death (Suokas et al. 2001; Wenzel et al. 2011), as well as the presence of any mental disorder (Cavanagh et al. 2003; Zubrick et al. 2016), and alcohol and drug abuse (Evans et al. 2004) for both genders. Suicidal ideation has been related to MDD; when this relationship was analyzed, the risk of suicide attempts was higher among female adolescents and young adults (Wittchen 1994), especially among younger girls (Bolger et al. 1989). This association may also be moderated by depressive symptoms. In males, a predisposition to suicidal behavior may be moderated by hopelessness traits, disruptiveness and conduct problems, and antisocial disorders (highly related to aggressiveness).

Finally, strong associations were found between suicidal behavior in youths and exposure to a history of mental disorders or substance abuse or previous suicidal behaviors in family members. Vulnerability in youths with a family history of mental disorders or suicidal behavior may be reflected in their tendencies to experience increased rates of mental or substance abuse disorders and suicidal behaviors (Mann et al. 1999).

\section{Female-specific risk factors}

Female adolescent and young adult victims of dating violence are at a higher risk of attempting suicide. This risk might be moderated by a higher predisposition to have internalizing symptoms and a higher exposure to psychological abuse (Temple et al. 2016). Dating violence might also be a mediator in the association between abortion and suicidal thoughts in youths, the magnitude of this association being related to the severity of the aggression (Ely et al. 2009), but there is no evidence of any mechanism. Nevertheless, there are no similar data in relation to suicidal behaviors.

Previous studies, including a systematic review, are in agreement with our meta-analysis results showing previous 
abortion as risk factor for suicide attempts. This association may be moderated by mental disorders or substance use (Mota et al. 2010; Coleman 2011). Mental disorders could be related to poor social support or psychological factors that lead to unintended pregnancy; due to a feeling of inability to cope with pregnancy, women decide to have an abortion (Mota et al. 2010). Another possibility is that some vulnerability factors (e.g., poor social support) related to abortion and mental disorders mediate the association (Fergusson et al. 2006). Finally, interpersonal difficulties are associated with suicide attempts among female youths. This may be explained by their greater predisposition to emotional problems, increasing the risk (Kaess et al. 2011). It is clear that all the factors discussed are both interrelated and related to the occurrence of suicidal behaviors. Further research is needed to clarify the pathways and mechanisms.

\section{Male-specific risk factors}

According to our results, access to means was a relevant risk factor among male adolescents and young adults, for both suicide attempts and death. Male-specific risk factors for suicide attempts included parental separation or divorce. Our findings are consistent with evidence that living in single-parent families may increase the risk of suicide attempts in male youths. However, other reports suggest that females are also at risk (Chau et al. 2014; Dieserud et al. 2015) or that the risks are similar in both genders (Fergusson and Lynskey 1995; Kim and Kim 2008). In addition, disruptiveness, hopelessness, and previous suicidal behavior among family or friends increased the risk of suicide attempts among males. For suicide death, externalizing disorders and drug abuse conferred a significant risk.

Previous research has shown that male adolescents tend to have slightly more symptoms of externalizing problems, such as aggressive, delinquent (Kaess et al. 2011), and antisocial behavior (Marmorstein and Iacono 2005), which may act as mediators for suicidal behaviors. Further research is needed on this topic. In addition, similar to our data, some studies have found higher rates of suicide attempts among individuals exposed to suicidal behavior in the family and peers (Randall et al. 2015), showing the influence of the environment in youths.

\section{Protective factors}

No evidence on protective factors for suicidal behaviors was found in either males or females, probably due to the scarcity of published data. A previous study has shown that the risk of suicidal behavior in adolescents of both genders is reduced by family support (Tseng and Yang 2015) and is possibly increased by weak relationships with peers. In general, females have a higher perception of peer support than males (Kerr et al. 2006). Our meta-analyses results did not find a protective association between peer support and suicidal behaviors in both genders. However, the primary data used for the analyses reported peer support but not perception of it. In addition, peer support might not always be positive, since close relationships with peers involved in suicidal behaviors or at high risk of it do not act as a protective factor (Prinstein et al. 2010). Further investigation is needed for the assessment of protective factors and suicidal behaviors in young people.

\section{Limitations}

This review has some limitations. We used the most widely recommended databases for psychiatric research, including Web of Science and PsycINFO (Löhönen et al. 2010), but were not able to search all available databases. Similar to previous systematic reviews (Devries et al. 2013; Maxwell et al. 2015), articles included came from a broad search strategy. Important information about vulnerable populations (e.g., incarcerated, veteran or active duty populations) was not considered because the inclusion criteria excluded institutionalized populations. No assessment was made of the suicide risk related to sexual orientation and gender identity. However, data analyzing these issues were already published (Miranda-Mendizábal et al. 2017).

The NOS was used to assess the quality of the included studies, but there is limited evidence on its validity (Wells et al. 2013). Nevertheless, its use is recommended by the Cochrane Collaboration. Random effect models were used for meta-analyses. They provide a very conservative estimate of the combined data with wider confidence intervals, as may be seen in some of our results. In addition, they may also lead to statistical values that are less likely to be significant (Borenstein et al. 2009).

For the association of gender and suicide death, only one cohort study was found, including individuals discharged from emergency departments; however, reference individuals were randomly selected from the general population, fulfilling our inclusion criteria. The wide heterogeneity observed in the meta-analyses of risk and protective factors may be explained by (1) the inclusion of observational studies that may have design flaws or tend to distort the magnitude or direction of associations (Stroup et al. 2000); (2) the differences in the adjustment; and (3) the possible reporting bias of the included studies. In addition, there were not enough studies to conduct meta-analyses for some risk, and especially, protective factors, particularly for suicide death. 


\section{Implications for prevention}

From a public health perspective, there is a need for the development and implementation of effective health policies and preventive strategies for suicidal behavior in adolescents and young adults, as well as for the early identification and reduction in the most prevalent risk factors. For example, reducing the different forms of interpersonal violence could help to diminish the prevalence of mental disorders and risky health and sexual behaviors (Wasserman et al. 2010). In addition, encouraging healthy behaviors (e.g., physical activity) may protect against some risk factors for suicide (Sheikh 2018). However, there is evidence that targeting individuals to change their behaviors will fail as long as the primary risk factors (e.g., childhood maltreatment) remain, because they would allow the appearance of new mediators (Sheikh et al. 2016).

Individual perception of social isolation may lead to impaired mental health and well-being. Strategies applying a more comprehensive approach (including community, school and family environment) (Fountoulakis et al. 2011) and increasing knowledge, to facilitate help-seeking behaviors, could be more effective (Riner and Saywell 2002). In addition, rather than implementing genderspecific prevention strategies, it is important for strategies to target and better address the most prevalent risk and protective factors to prevent suicidal behaviors.

\section{Implications for research}

Although gender differences in youth suicidal behavior have been identified, further research is needed. We encourage longitudinal research assessing the role of sociodemographic variables (e.g., socioeconomic status, ethnicity) in suicidal behavior among young persons. Additional research is also needed on academic (e.g., academic failure) and protective factors (e.g., resilience) in young females and males, as well as research on access to means, externalizing problems, and a family history of mental disorders and abuse among young females, and relationship problems, bipolar and eating disorders in young males. To reduce suicide mortality, information is needed on related pathways in both genders. Importantly, the development and implementation of preventive strategies should include gender preferences and context. To do so, youth preferences with respect to public health interventions should be assessed. Finally, as gender is one of the most important social determinants of health inequalities (Solar and Irwin 2010), efforts should be made to reduce the gender gap in health issues, particularly during adolescence and young adulthood, which are periods of special vulnerability.
Funding Ministerio de Sanidad, Consumo y Bienestar Social, PSND (Exp. 2015I015), Instituto de Salud Carlos III-FEDER (PI13/00343), Fondo de Investigación Sanitaria-ISCIII (CD12/00440; CM14/ 00125), DIUE Generalitat de Catalunya (2017 SGR 452), and European Regional Development Fund (PSI2017-90650-REDT).

\section{Compliance with ethical standards}

\section{Conflict of interest None.}

Ethical Statement This study is a systematic review; ethics committee approval is not required.

Open Access This article is distributed under the terms of the Creative Commons Attribution 4.0 International License (http://creative commons.org/licenses/by/4.0/), which permits unrestricted use, distribution, and reproduction in any medium, provided you give appropriate credit to the original author(s) and the source, provide a link to the Creative Commons license, and indicate if changes were made.

\section{References}

Afifi TO, Cox BJ, Katz LY (2007) The associations between health risk behaviours and suicidal ideation and attempts in a nationally representative sample of young adolescents. Can J Psychiatry 52:666-674

Beautrais AL (2002) Gender issues in youth suicide. Emerg Med Australas 14:35-42

Beautrais AL (2003) Suicide and serious suicide attempts in youth: a multiple-group comparison study. Am J Psychiatry 160:1093-1099. https://doi.org/10.1176/appi.ajp.160.6.1093

Beautrais L, Joyce PR, Mulder RT (1996) Risk factors for serious suicide attempts among youths aged 13 through 24 years. J Am Acad Child Adolesc Psychiatry 35:1174-1182. https://doi.org/ 10.1097/00004583-199609000-00015

Bellis MA, Hughes K, Leckenby N et al (2014) Adverse childhood experiences and associations with health-harming behaviours in young adults: surveys in eight eastern European countries. Bull World Health Organ 92:641-655B

Boeninger DK, Masyn KE, Feldman BJ, Conger PD (2010) Sex differences in developmental trends of suicide ideation, plans, and attempts among European American adolescents. Suicide Life Threat Behav 40:451-464. https://doi.org/10.1521/suli. 2010.40.5.451.Sex

Bolger N, Downey G, Walker E, Steininger P (1989) The onset of suicidal ideation in childhood and adolescence. J Youth Adolesc 18:175-190. https://doi.org/10.1007/BF02138799

Borenstein M, Hedges L, Higgins J, Rothstein H (2009) Fixed-effect versus random-effects models. In: Introduction to meta-analysis. Wiley, Chichester

Borges G, Angst J, Nock MK et al (2008) Risk factors for the incidence and persistence of suicide-related outcomes: a 10-year follow-up study using the National Comorbidity Surveys. J Affect Disord 105:25-33

Canetto SS (2008) Women and suicidal behavior: a cultural analysis. Am J Orthopsychiatry 78:259-266. https://doi.org/10.1037/ a0013973

Canetto SS, Sakinofsky I (1998) The gender paradox in suicide. Suicide Life-Threat Behav 28:1-23

Cavanagh J, Carson A, Sharpe M, Lawrie S (2003) Psychological autopsy studies of suicide: a systematic review. Psychol Med 33:S0033291702006943. https://doi.org/10.1017/ S0033291702006943 
Chau K, Kabuth B, Chau N (2014) Gender and family disparities in suicide attempt and role of socioeconomic, school, and healthrelated difficulties in early adolescence. Biomed Res Int 2014:1-13. https://doi.org/10.1155/2014/314521

Coleman PK (2011) Abortion and mental health: quantitative synthesis and analysis of research published 1995-2009. Br J Psychiatry 199:180-186. https://doi.org/10.1192/bjp.bp.110. 077230

Devries KM, Mak JY, Bacchus LJ et al (2013) Intimate partner violence and incident depressive symptoms and suicide attempts: a systematic review of longitudinal studies. PLoS Med 10:e1001439. https://doi.org/10.1371/journal.pmed.1001439

Dieserud G, Gerhardsen RM, Van Weghe H, Corbett K (2015) Adolescent suicide attempts in Bærum, Norway, 1984-2006. Crisis 31:255-264

Eaton D, Kann L, Jinchen S (2012) Youth risk behavior surveillance-United States, 2011. MMWR Surveill Summ 61:1-162

Ely GE, Nugent WR, Flaherty C (2009) The relationship between dating violence and psychosocial problems in a sample of adolescent pregnancy termination patients. Violence Vict 24:577-590. https://doi.org/10.1891/0886-6708.24.5.577

Evans E, Hawton K, Rodham K (2004) Factors associated with suicidal phenomena in adolescents: a systematic review of population-based studies. Clin Psychol Rev 24:957-979. https:// doi.org/10.1016/j.cpr.2004.04.005

Evans E, Hawton K, Rodham K et al (2005) The prevalence of suicidal phenomena in adolescents: a systematic review of population-based studies. Suicide Life-Threat Behav 35:239-250. https://doi.org/10.1521/suli.2005.35.3.239

Fergusson DM, Lynskey M (1995) Childhood circumstances, adolescent adjustment, and suicide attempts in a New Zealand birth cohort. J Am Acad Child Adolesc Psychiatry 34:612-622

Fergusson D, Horwood J, Lynskey M (1993) Prevalence and comorbidity of DSM-III-R diagnoses in a birth cohort of 15 year olds. J Am Acad Child Adolesc Psychiatry 32:1127-1134

Fergusson DM, Horwood LJ, Ridder EM (2006) Abortion in young women and subsequent mental health. J Child Psychol Psychiatry Allied Discip 47:16-24. https://doi.org/10.1111/j.14697610.2005.01538.x

Finkelstein Y, Macdonald EM, Hollands S et al (2015) Long-term outcomes following self-poisoning in adolescents: a populationbased cohort study. Lancet Psychiatry 2:532-539. https://doi.org/ 10.1016/S2215-0366(15)00170-4

Fountoulakis KN, Gonda X, Rihmer Z (2011) Suicide prevention programs through community intervention. J Affect Disord 130:10-16. https://doi.org/10.1016/j.jad.2010.06.009

Gould M, Velting D, Kleinman M et al (2004) Teenagers' attitudes about coping strategies and help-seeking behavior for suicidality. J Am Acad Child Adolesc Psychiatry 43:1124-1133

Higgins J, Green S (2008) Cochrane handbook for systematic reviews of interventions. The Cochrane Collaboration

Higgins JPT, Thompson SG (2002) Quantifying heterogeneity in a meta-analysis. Stat Med 21:1539-1558. https://doi.org/10.1002/ $\operatorname{sim} .1186$

Kaess M, Parzer P, Haffner J et al (2011) Explaining gender differences in non-fatal suicidal behaviour among adolescents: a population-based study. BMC Public Health 11:597. https://doi. org/10.1186/1471-2458-11-597

Kerr DCR, Preuss LJ, King CA (2006) Suicidal adolescents' social support from family and peers: gender-specific associations with psychopathology. J Abnorm Child Psychol 34:103-114. https:// doi.org/10.1007/s10802-005-9005-8

Kim HS, Kim HS (2008) Risk factors for suicide attempts among Korean adolescents. Child Psychiatry Hum Dev 39:221-235

Kokkevi A, Rotsika V, Arapaki A, Richardson C (2012) Adolescents' self-reported suicide attempts, self-harm thoughts and their correlates across 17 European countries. J Child Psychol Psychiatry Allied Discip 53:381-389. https://doi.org/10.1111/j. 1469-7610.2011.02457.x

Lewinsohn PM, Rohde P, Seeley JR, Baldwin CL (2001) Gender differences in suicide attempts from adolescence to young adulthood. J Am Acad Child Adolesc Psychiatry 40:427-434. https://doi.org/10.1097/00004583-200104000-00011

Löhönen J, Isohanni M, Nieminen P, Miettunen J (2010) Coverage of the bibliographic databases in mental health research. Nord $\mathbf{J}$ Psychiatry 64:181-188

Mann JJ, Waternaux C, Haas GL, Malone KM (1999) Toward a clinical model of suicidal behavior in psychiatric patients. Am J Psychiatry 156:181-189. https://doi.org/10.1176/ajp.156.2.181

Marmorstein NR, Iacono WG (2005) Longitudinal follow-up of adolescents with late-onset antisocial behavior: a pathological yet overlooked group. J Am Acad Child Adolesc Psychiatry 44:1284-1291. https://doi.org/10.1097/01.chi.0000181039. 75842.85

Mars B, Heron J, Crane C et al (2014) Differences in risk factors for self-harm with and without suicidal intent: findings from the ALSPAC cohort. J Affect Disord 168:407-414. https://doi.org/ 10.1016/j.jad.2014.07.009

Maxwell L, Devries K, Zionts D et al (2015) Estimating the effect of intimate partner violence on women's use of contraception: a systematic review and meta-analysis. PLoS ONE 10:e0118234. https://doi.org/10.1371/journal.pone.0118234

Mergl R, Koburger N, Heinrichs K et al (2015) What are reasons for the large gender differences in the lethality of suicidal acts? An epidemiological analysis in four European countries. PLoS ONE 10:1-18. https://doi.org/10.1371/journal.pone.0129062

Miranda-Mendizábal A, Castellví P, Parés-Badell O et al (2017) Sexual orientation and suicidal behaviour in adolescents and young adults: systematic review and meta-analysis. $\mathrm{Br} \mathrm{J}$ Psychiatry 211:77-87. https://doi.org/10.1192/bjp.bp.116. 196345

Mota N, Burnett M, Sareen J (2010) Associations between abortion, mental disorders, and suicidal behaviour in a nationally representative sample. Can J Psychiatry 55:239-247

Nock MK, Grief Green J, Hwang I et al (2013) Prevalence, correlates, and treatment of lifetime suicidal behavior among adolescents. JAMA Psychiatry 70:300. https://doi.org/10.1001/2013.jamapsy chiatry. 55

ÓBrien BS, Sher L (2013) Child sexual abuse and the pathophysiology of suicide in adolescents and adults. Int $\mathrm{J}$ Adolesc Med Health 25:201-205

O’Connor RC, Smyth R, Williams JMG (2015) Intrapersonal positive future thinking predicts repeat suicide attempts in hospitaltreated suicide attempters. J Consult Clin Psychol 83:169-176. https://doi.org/10.1037/a0037846

Peter T, Roberts LW (2010) "Bad" boys and "Sad" girls? Examining internalizing and externalizing effects on parasuicides among youth. J Youth Adolesc 39:495-503. https://doi.org/10.1007/ s10964-009-9498-5

Prinstein MJ, Heilbron N, Guerry JD et al (2010) Peer influence and nonsuicidal self injury: longitudinal results in community and clinically-referred adolescent samples. J Abnorm Child Psychol 38:669-682. https://doi.org/10.1007/s10802-010-9423-0

Randall JR, Nickel NC, Colman I (2015) Contagion from peer suicidal behavior in a representative sample of American adolescents. J Affect Disord 186:219-225

Renaud J, Berlim MT, McGirr A et al (2008) Current psychiatric morbidity, aggression/impulsivity, and personality dimensions in child and adolescent suicide: a case-control study. J Affect Disord 105:221-228. https://doi.org/10.1016/j.jad.2007.05.013

Rhodes A (2013) Youth suicide in Canada: distinctions among boys and girls. Healthc Q 16:11-13 
Rhodes AE, Boyle MH, Bridge JA et al (2014a) Antecedents and sex/gender differences in youth suicidal behavior. World $\mathrm{J}$ Psychiatry 4:120-132. https://doi.org/10.5498/wjp.v4.i4.120

Rhodes AE, Lu H, Skinner R (2014b) Time trends in medically serious suicide-related behaviours in boys and girls. Can J Psychiatry 59:556-560

Rickwood D, Deane FP, Wilson CJ, Ciarrochi JV (2005) Young peoplés help-seeking for mental health problems. Aust e-J Adv Ment Health 4:218-251. https://doi.org/10.5172/jamh.4.3.218

Riner ME, Saywell RM (2002) Development of the social ecology model of adolescent interpersonal violence prevention (SEMAIVP). J Sch Health 72:65-70

Sheikh MA (2018) Childhood physical maltreatment, perceived social isolation, and internalizing symptoms: a longitudinal, threewave, population-based study. Eur Child Adolesc Psychiatry 27:481-491. https://doi.org/10.1007/s00787-017-1090-z

Sheikh MA, Abelsen B, Olsen JA (2016) Clarifying associations between childhood adversity, social support, behavioral factors, and mental health, health, and well-being in adulthood: a population-based study. Front Psychol. https://doi.org/10.3389/ fpsyg.2016.00727

Solar O, Irwin A (2010) A conceptual framework for action on the social determinants of health. Geneva

Stroup D, Berlin J, Morton S (2000) Meta-analysis of observational studies in epidemiology: a proposal for reporting. JAMA 283:2008-2012

Suokas J, Suominen K, Isometsä E et al (2001) Long-term risk factors for suicide mortality after attempted suicide-findings of a 14-year follow-up study. Acta Psychiatr Scand 104:117-121

Temple J, Choi H, Elmquist J et al (2016) Psychological abuse, mental health, and acceptance of dating violence among adolescents. J Adolesc Heal 59:197-202

Thompson MP, Light LS (2011) Examining gender differences in risk factors for suicide attempts made 1 and 7 years later in a nationally representative sample. J Adolesc Health 48:391-397. https://doi.org/10.1016/j.jadohealth.2010.07.018

Tseng FY, Yang HJ (2015) Internet use and web communication networks, sources of social support, and forms of suicidal and nonsuicidal self-injury among adolescents: Different patterns between genders. Suicide Life-Threat Behav 45:178-191. https://doi.org/10.1111/sltb.12124

Värnik A, Kõlves K, van der Feltz-Cornelis CM et al (2008) Suicide methods in Europe: a gender-specific analysis of countries participating in the "European Alliance Against Depression". J Epidemiol Commun Health 62:545-551. https://doi.org/10. 1136/jech.2007.065391

Wasserman D, Cheng Q, Jiang G-X (2005) Global suicide rates among young people aged 15-19. World Psychiatry 4:114-120

Wasserman D, Carli V, Wasserman C et al (2010) Saving and Empowering Young Lives in Europe (SEYLE): a randomized controlled trial. BMC Public Health 10:1-14

Wells G, Shea B, O'Connell D et al (2013) The Newcastle-Ottawa Scale (NOS) for assessing the quality of nonrandomised studies in meta-analyses. http://www.ohri.ca/programs/clinical_epide miology/oxford.asp

Wenzel A, Berchick ER, Tenhave T et al (2011) Predictors of suicide relative to other deaths in patients with suicide attempts and suicide ideation: a 30-year prospective study. J Affect Disord 132:375-382. https://doi.org/10.1016/j.jad.2011.03.006

Wilcox HC, Storr CL, Breslau N (2009) Posttraumatic stress disorder and suicide attempts in a community sample of urban American young adults. Arch Gen Psychiatry 66:305-311

Wilcox HC, Arria AM, Caldeira KM et al (2010) Prevalence and predictors of persistent suicide ideation, plans, and attempts during college. J Affect Disord 127:287-294

Wittchen H-U (1994) Reliability and validity studies of the WHOComposite International Diagnostic Interview (CIDI): a critical review. J Psychiatr Res 28:57-84. https://doi.org/10.1016/00223956(94)90036-1

World Health Organization (2014) Preventing suicide, a global imperative. Geneva

World Health Organization (2016) Suicide data. http://www.who.int/ mental_health/prevention/suicide/suicideprevent/en/

Wunderlich U, Bronisch T, Wittchen H-U, Carter R (2001) Gender differences in adolescents and young adults with suicidal behaviour. Acta Obstet Gynecol Scand 104:332-339

Zubrick SR, Hafekost J, Johnson SE et al (2016) Suicidal behaviours: prevalence estimates from the second Australian Child and Adolescent Survey of Mental Health and Wellbeing. Aust New Zeal J Psychiatry. https://doi.org/10.1177/0004867415622563

Publisher's Note Springer Nature remains neutral with regard to jurisdictional claims in published maps and institutional affiliations.

\section{Affiliations}

\section{Andrea Miranda-Mendizabal ${ }^{1,2} \cdot$ Pere Castellvi $^{1,3} \cdot$ Oleguer Parés-Badell $^{1} \cdot$ Itxaso Alayo $^{1,4} \cdot$ José Almenara $^{5}$. Iciar Alonso ${ }^{6}$ - Maria Jesús Blasco ${ }^{1,2,4} \cdot$ Annabel Cebrià $^{7} \cdot$ Andrea Gabilondo $^{8,9} \cdot$ Margalida Gili $^{10,11}$. Carolina Lagares $^{12}$ - José Antonio Piqueras ${ }^{13} \cdot$ Tiscar Rodríguez-Jiménez $^{13}$ - Jesús Rodríguez-Marín ${ }^{13}$. Miquel Roca ${ }^{10,11} \cdot$ Victoria Soto-Sanz $^{13} \cdot$ Gemma Vilagut $^{1,4} \cdot$ Jordi Alonso $^{1,2,4}$}

1 Health Services Research Group, IMIM-Institut Hospital del Mar d́Investigacions Mèdiques, PRBB Building. Doctor Aiguader 88, 08003 Barcelona, Spain

2 Department of Health and Experimental Sciences, Pompeu Fabra University (UPF), Barcelona, Spain

3 Department of Psychology, Jaen University, Jaén, Spain

4 CIBER Epidemiología y Salud Pública (CIBERESP), Madrid, Spain
5 Preventive Medicine Area and Public Health, University of Cádiz, Cádiz, Spain

6 Morales Meseguer Hospital, Murcia, Spain

7 Department of Mental Health, Corporació Sanitaria Parc Taulí, Sabadell, Spain

8 Outpatient Mental Health Care Network, Osakidetza-Basque Health Service, San Sebastian, Spain

9 Mental Health and Psychiatric Care Research Unit, BioDonosti Health Research Institute, San Sebastian, Spain 
10 Institut Universitari d'Investigació en Ciències de la Salut (IUNICS-IDISPA), University of Balearic Islands,

Palma de Mallorca, Spain

11 Network of Preventive Activities and Health Promotion, University of Balearic Islands, Palma de Mallorca, Spain
12 Department of Statistics and Operative Research, University of Cádiz, Cádiz, Spain

13 Department of Health Psychology, Miguel Hernandez University of Elche, Elche, Spain 